\title{
Condição imunológica de bovinos das raças Holandesa e Nelore frente a Babesia bovis e B. bigemina em duas regiões do Estado de São Paulo ${ }^{1}$
}

\author{
Lourdes A.Z. D’Andrea ${ }^{2 *}$, Izidoro F. Sartor ${ }^{3}$, Cláudio R. Madruga ${ }^{4}$, Selma B.Z. \\ Freitas $^{5}$, Lúcio B. Kroll ${ }^{6}$ e Sérgio N. Kronka ${ }^{7}$
}

\begin{abstract}
D’Andrea L.A.Z., Sartor I.F,, Madruga C.R., Freitas S.B.Z., Kroll L.B. \& Kronka S.N. 2005. [Immunological condition of cattle in Holstein and Nelore breed in regard to Babesia bovis and B. bigemina in two regions of the State of São Paulo.] Condição imunológica de bovinos das raças Holandesa e Nelore frente a Babesia bovis e B. bigemina em duas regiões do Estado de São Paulo. Pesquisa Veterinária Brasileira 26(2):74-78.. Seção de Biologia Médica do Instituto Adolfo Lutz, Laboratório Regional de Presidente Prudente, Av. Cel José Soares Marcondes 2357, Presidente Prudente, SP 19013-050, Brazil. E-mail: zampieri@ial.sp.gov.br

The immunological reply of a population to an infectious agent can vary between races and handling of this population. Regional research becomes important, in order to know the interrelation between the agent and its host. In this way, the occurrence of immunoglobulins of class $\mathrm{G}$, antiBabesia bovis and anti-Babesia bigemina in the Nelore (Bos indicus) and Hostein breed (Bos taurus), was investigated in two regions of the State of São Paulo, $300 \mathrm{~km}$ distant from each other. For the indirect method of ELISA, 1,161 bovine serum samples were tested. The medium frequencies of antibodies showed that in the two regions exists an enzootic stability for B. bovis in both breeds studied; even so there was a tendency of marginal area for the Nelore breed in one of the regions. Regarding B. bigemina, in both regions exists enzootic stability for the Hostein and enzootic instability for the Nelore breed. Therefore, acute cases of the disease or specific outbreaks by B. bigemina infection in the Nelore breed may occur in these regions.
\end{abstract}

INDEX TERMS: Babesia bovis, Babesia bigemina, ELISA, cattle, immunological condition.

RESUMO.- A resposta imunológica de uma população frente a um agente infeccioso pode variar entre as raças e o manejo dessa população. Dessa maneira, torna-se relevante a pesquisa regional, visando o conhecimento da inter-relação do agente com seu hospedeiro. Partindo desses pressupostos, investigouse a ocorrência de imunoglobulinas da classe $\operatorname{lgG}$, anti-Babesia

\footnotetext{
${ }^{1}$ Recebido em 20 de fevereiro de 2005.

Aceito para publicação em 17 de outubro de2005.

2 Seção de Biologia Médica, Laboratório Regional de Presidente Prudente, Instituto Adolfo Lutz, Av. Cel José Soares Marcondes 2357, Presidente Prudente, SP 19013-050, Brasil. *Autor para correspondência. E-mail: zampieri@ial.sp.gov.br

${ }^{3}$ Curso de Pós-Graduação, Unoeste/Unesp, Rodovia Raposo Tavares Km 572, Presidente Prudente, SP 19067-175.

${ }^{4}$ Centro Nacional de Pesquisa de Gado de Corte, Embrapa, Caixa Postal 154, Campo Grande, MS 79002-970.

5 Pós-Graduanda, Universidade do Oeste Paulista (Unoeste), Av, José Bongiovani 700, Presidente Prudente, 19050-900 SP.

${ }^{6}$ Docente Pós-Graduação, Unoeste, São Paulo, SP.

${ }^{7}$ Docente Pós-Graduação, Unoeste, São Paulo, SP.
}

bovis e anti-B. bigemina nas raças Nelore (Bos indicus) e Holandesa (Bos taurus), em duas regiões do Estado de São Paulo, distantes a $300 \mathrm{~km}$. Pelo método de ELISA indireto, foram testadas 1.161 amostras de soro de bovinos. As frequiências médias de anticorpos mostraram que ambas as regiões se encontram em situação de estabilidade enzoótica para $B$. bovis para ambas as raças estudadas, embora haja tendência para área marginal na região de Presidente Prudente para raça Nelore. No referente a B. bigemina ambas as regiões são de estabilidade enzoótica para a raça Holandesa e de instabilidade enzoótica para a raça Nelore. Essa constatação é um alerta sanitário, pois casos agudos da doença ou surtos específicos de $B$. bigemina na raça Nelore podem ocorrer nessas regiões.

TERMOS DE INDEXAÇÃO: Babesia bovis, Babesia bigemina, ELISA, bovino, condição imunológica, Brasil.

\section{INTRODUÇÃO}

As babesioses, cujos agentes etiológicos são Babesia bovis e Babesia bigemina, são patógenos transmitidos, principalmente, pelas for- 
mas jovens do carrapato Boophilus microplus, constituindo-se entre os principais problemas sanitários dos rebanhos bovinos de corte e de leite (Wright \& Goodger 1988). Essas enfermidades provocam grandes prejuízos à criação bovina não apenas pela mortalidade que causam, mas também pela redução na produção de carne e leite, além de custos indiretos com medidas preventivas e tratamento dos animais (Araújo et al. 1998). Além da importância destacada na pecuária, essas enfermidades constituem-se também em zoonoses (Suarez et al. 1997, Kurt \& Girginkardesler 2001).

Nas áreas de estabilidade enzoótica os efeitos dessas doenças são minimizados em decorrência da exposição precoce e gradativa dos animais aos agentes, logo após o nascimento, possibilitando o desenvolvimento de imunidade (Corrier et al. 1978). Entretanto, quando animais provenientes de áreas de instabilidade enzoótica são alocados em outras, consideradas de estabilidade enzoótica, essas enfermidades se manifestam de forma aguda, podendo levar o animal à morte ou a transtornos graves, como o abortamento.

Segundo Madruga et al. (2000), os estudos de prevalência desses hemoparasitas são importantes para o conhecimento da condição epidemiológica de uma região, indicando sua situação se há instabilidade ou estabilidade enzoótica e, conseqüientemente, se há ou não necessidade de adoção de medidas sanitárias, quando se depara com indivíduos enfermos ou em surtos da doença.

Também uma área de estabilidade pode se tornar instável por certos procedimentos do manejo como, por exemplo, excesso de combate ao B. microplus ou mesmo quando sua população é naturalmente escassa, provocando com isso um baixo inóculo ao agente e conseqüentemente baixa imunidade.

Por ser um método prático, sensível e específico, a imunoadsorção enzimática (ELISA) é o que confere melhores resultados para o levantamento da situação epidemiológica (Araújo et al. 1998). Tendo em vista a importância das babesioses nas regiões tropicais e, pela escassez de pesquisas de prevalência desses hemoparasitas no Estado de São Paulo, este trabalho teve por objetivo estudar a situação imunológica de $B$. bovis e $B$. bigemina em bovinos das espécies $B$. taurus e $B$. indicus, nas regiões de Presidente Prudente e Avaré, São Paulo, utilizando-se o método de ELISA indireto.

\section{MATERIAL E MÉTODOS}

\section{Áreas de estudo}

O levantamento foi realizado com amostras de soros de bovinos adultos de dezoito propriedades da região de Avaré, localizada a sudoeste do Estado de São Paulo, na longitude $48^{0} 55^{\prime}$ e latitude $23^{0} 06$ '. Essa região compreende uma área de $1.219,6 \mathrm{~km}^{2}$ e possui uma população estimada de 373.958 bovinos. O clima é quente, com temperaturas médias de $18^{\circ} \mathrm{C}$.

Também foram utilizados animais de 15 propriedades da região de Presidente Prudente. A região é localizada no extremo oeste do Estado de São Paulo, na longitude $22^{0} 07^{\prime}$ e latitude $51^{0} 22^{\prime}$, compreendendo uma área de $9.556,56 \mathrm{~km}^{2}$. Essa região possui uma população estimada de 2.400 .000 bovinos. O clima é tropical seco e úmido, com temperaturas médias de $28^{\circ} \mathrm{C}$. A distância compreendida entre as duas áreas estudadas é de aproximadamente 300 km.

\section{Animais e coleta de material}

No Quadro 1 estão contidos os números de propriedades e de repetições.

\section{Quadro 1. Número de propriedades e de bovinos da raça Holandesa e Nelore, nas regiões de Avaré e Presidente Prudente, São Paulo}

\begin{tabular}{|c|c|c|c|c|}
\hline \multirow[t]{3}{*}{ Municípios } & \multirow{2}{*}{\multicolumn{2}{|c|}{$\frac{\mathrm{N}^{\mathrm{O}} \text { de propriedades }}{\text { Raças }}$}} & \multirow{2}{*}{\multicolumn{2}{|c|}{$\frac{\mathrm{N}^{\mathrm{O}} \text { de bovinos analisados }}{\text { Raças }}$}} \\
\hline & & & & \\
\hline & Holandesa & Nelore & Holandesa & Nelore \\
\hline Avaré & 11 & 7 & 245 & 245 \\
\hline Presidente Prudente & 10 & 5 & 317 & 354 \\
\hline Total & 21 & 12 & 562 & 599 \\
\hline
\end{tabular}

\section{Antígeno}

Os lisados de Babesia bovis e B. bigemina foram obtidos de bezerros criados no Mato Grosso do Sul em áreas de isolamento, segundo Kessler \& Schenk (1998) e, cedidos pelo Centro Nacional de Pesquisa de Gado de Corte em Campo Grande, MS.

\section{Ensaio de imunoadsorção enzimática (ELISA) indireta}

O ensaio foi desenvolvido a partir da solubilização de antígenos de merozoítos semipurificados, por centrifugação diferencial a partir de hemácias parasitadas, obtidas segundo técnica descrita por Madruga et al. (1997) para B. bigemina e por Madruga et al. (2000) para B. bovis. Realizou-se o ensaio de ELISA indireto, para detecção de anticorpos da classe $\lg G$ anti-B. bovis e anti-B. bigemina, utilizando-se microplacas 96 orifícios (Costar 3590) para titulação. As microplacas foram sensibilizadas com extrato total diluído a 1:2.000 para $B$. bovis e a 1:4.000 para $B$. bigemina em tampão carbonato/bicarbonato $\left(\mathrm{Na}_{2} \mathrm{CO}_{3}\right.$ $\left.200 \mathrm{mM}, \mathrm{NaHCO}_{3} 199 \mathrm{mM}\right) \mathrm{pH} 9,2(100 \mu \mathrm{l} /$ poço), que foram incubadas durante 4 horas a $4^{\circ} \mathrm{C}$. Quando não utilizadas de imediato, as placas foram armazenadas a temperaturas de $-70^{\circ} \mathrm{C}$ até o momento de sua utilização. Em seguida, submetidas a cinco lavagens com PBS "tween" 20 a $0,1 \%$ (PBST) $\left(\mathrm{Na}_{2} \mathrm{HPO}_{4} \cdot 2 \mathrm{H}_{2} \mathrm{O} 10 \mathrm{mM}, \mathrm{NaHPO}_{4} \cdot 2 \mathrm{H}_{2} \mathrm{O} \quad 6,4 \mathrm{mM}, \mathrm{NaCl}\right.$ $99 \mathrm{mM}) \mathrm{pH} 7,2$. Foram distribuídos os soros controle positivo alto, negativo e testes, diluídos a 1:1.000 em PBST, e controle positivo fraco diluído a 1:3.000 em PBST (100 $\mu \mathrm{l} /$ poço). As microplacas foram incubadas em câmara úmida a $37^{\circ} \mathrm{C}$ por 45 minutos, sendo efetuadas cinco lavagens, conforme descrito anteriormente. Em seguida, adicionados $50 \mu \mathrm{l} /$ poço de imunoglobulina de coelho anti-IgG bovina, conjugada com fosfatase alcalina (Sigma A - 0705), diluída a 1:12.000 em PBST para B. bovis e 1:15.000 em PBST para B. bigemina. As placas novamente incubadas em câmara úmida, a $37^{\circ} \mathrm{C}$ por 30 minutos e depois lavadas 10 vezes com PBST. O substrato p-nitrofenil fosfato "fast" (Sigma N 2770) foi diluído em $5 \mathrm{~mL}$ de tampão ( $5 \mathrm{~mL}$ de $\mathrm{H}_{2} \mathrm{O}$ deionizada dissolvido com uma pastillha de tampão "fast") foi adicionado em volume de 50 $\mu \mathrm{l} /$ poço. A reação foi bloqueada após 30 minutos com $\mathrm{NaCl}$ 0,2 M (100 $\mu \mathrm{l} /$ poço). A leitura dos resultados foi realizada em espectrofotômetro multicanal para microplacas de 96 orifícios, com filtro de $405 c ̧ \mathrm{~m}$, em absorbância e os valores da densidade óptica (D.O.) corrigidos com a aplicação da seguinte fórmula para o fator de ajuste $(F)$ :

$$
F=\frac{P O-N O}{P t-N t}
$$

Onde: $F=$ Fator de ajuste da DO, $P O=$ Média das DOs de soros controle positivo do teste de referência padrão, $N O=$ Média das DOs de soros controle negativo do teste de referência padrão, $P t=$ Média das DOs de soros controle positivo da placa teste, $N t=$ Média das DOs de soros controle negativo da placa teste.

Para o ELISA a linha de corte ("cut-off") foi estabelecida usando a média das DOs de 20 soros de animais livres de infecção por B. bovis e $B$. bigemina realizados em duplicatas, utilizando-se a mesma metodologia empregada para análise das amostras, somada a três desvios padrões. O “cut-off” padrão para $B$. bovis foi de 0,096 e para $B$. bigemina foi de 0,114 
O "cut-off" de cada placa foi estabelecido da mesma forma que o "cut-off" padrão, utilizando-se cinco soros de animais livres de infecção por Babesia spp, em duplicatas, cujas médias das DOs foram corrigidas pela fórmula de ajuste somada a três desvios padrões. Para maior confiança da análise dos resultados, calculou-se a média entre "cutoff" da placa e o "cut-off" padrão, sendo este valor utilizado para interpretar os valores após o ajuste. Foi considerada amostra positiva quando o valor em DO foi maior ou igual à média do valor do "cut-off".

\section{Análise estatística}

Utilizou-se a metodologia de análise descritiva dos dados por região, por raça e por propriedades, considerando-se os dois agentes, B. bovis e B. bigemina. Foi calculada a porcentagem média dos soros reagentes e não reagentes para as respectivas babesias, de acordo com as categorias acima descritas, uma vez que as comparações foram feitas com os limites críticos de 0,75 a fim de verificar se a região é de estabilidade enzoótica ou não. A análise estatística foi feita baseada no teste " $t$ de Student", a 5\% de probabilidade para comparação de diferenças entre duas médias.

\section{RESULTADOS}

A análise soro-epidemiológica das 1.161 amostras de soro encontra-se nos Quadros 2 e 3.

O Quadro 2 mostra que a raça Nelore se apresenta instável para a $B$. bigemina.

O Quadro 3 mostra que embora haja estabilidade enzoótica para um mesmo parasita nas diferentes regiões, pode haver diferenças significativas na ocorrência de anticorpos entre elas.

Quadro 2. Distribuição da soroprevalência de cada região segundo agente espécie, raça, números de bovinos e condição imunológica, considerando-se como estabilidade enzoótica áreas com freqüência de anticorpos $\geq 75 \%$

\begin{tabular}{ccccc}
\hline Agente & Raça & $\mathrm{N}^{0}$ de bovinos & Município & Soroprevalência (\%) \\
\hline $\begin{array}{c}\text { Babesia } \\
\text { bovis }\end{array}$ & Holandesa & 245 & Avaré & 90,12 \\
& & 317 & Pres. Prudente & 96,50 \\
& Nelore & 245 & Avaré & 92,98 \\
Babesia & Holandesa & 245 & Pres. Prudente & 78,08 \\
bigemina & & 317 & Pres. Prudente & 81,80 \\
& \multirow{2}{*}{ Nelore } & 245 & Avaré & 67,55 \\
& & 354 & Pres. Prudente & 65,77
\end{tabular}

\section{DISCUSSÃO}

\section{Soroprevalência entre Babesia bovis e $B$. bigemina}

Para efeito de classificação das áreas utilizou-se os critérios de Mahoney \& Rosse (1972), Mahoney (1975), Smith (1980) e Leite et al. (1989) os quais caracterizam como estabilidade enzoótica as áreas cujos rebanhos possuem freqüência de anticorpos acima de 75\%, áreas de instabilidade enzoótica, aquelas cujos rebanhos apresentam frequiência de anticorpos inferiores a 75\%; e, áreas marginais aquelas cujas freqüências de anticorpos estão muito próximas do limite. Como o experimento demonstrou haver diferença significativa entre raças de $B$. taurus e $B$. indicus, levou-se esse fator em consideração na ordem de discussão.

Quando comparadas ambas as espécies, Babesia bovis e $B$. bigemina (Quadros 2 e 3) constata-se um maior número de animais com anticorpos anti-B. bovis em ambas as regiões que se enquadram totalmente como áreas de estabilidade enzoótica. A mesma situação não ocorreu para $B$. bigemina, onde áreas de instabilidade enzoótica foram constatadas em ambos os municípios para a raça Nelore. Também nesses quadros fica evidenciado que os rebanhos Nelores possuem menor freqüência de anticorpos que os rebanhos Holandeses. Esse fato poderia ser justificado no desenvolvimento da relação entre transmissão do parasito e o hospedeiro. Sabe-se que $B$. bovis é transmitida pelo estágio larval de $B$. microplus e que $B$. bigemina é transmitida pelos estágios de ninfa a adulto (Kessler \& Schenk 1998). A rejeição maior do hospedeiro frente a $B$. microplus está compreendida nas 24 primeiras horas após a infestação constituindo-se assim este período, em uma fase crítica para a sobrevivência de B. microplus (Bennett 1974). Nesse período, pode ocorrer rejeição de $30 \%$ a $80 \%$ (Wagland 1979), com algumas raças resistentes rejeitando acima de $90 \%$ de larvas (Roberts 1968). Kemp et al. (1976) constataram que também mais tempo é gasto pelas larvas para a fixação em animais de alta resistência prejudicando a instalação da babesia. As raças inclusas na espécie de $B$. indicus são citadas como sendo as de maior resistência a $B$. microplus (Willadsen 1986, Sartor et al. 1992) devido a eficiência de sua auto-limpeza, eliminando a maioria das larvas, diminuindo dessa maneira, a continuidade de seu ciclo e com isso, a possibilidade de transmissão de B. bigemina. Provavelmente, seria um dos

Quadro 3. Diferenças nas taxas de anticorpos anti Babesia bovis e B. bigemina (ELISA) nos rebanhos Holandês e Nelore

\begin{tabular}{|c|c|c|c|c|c|c|}
\hline \multicolumn{2}{|c|}{ Comparações } & \multirow[b]{2}{*}{ vs } & \multirow[b]{2}{*}{2 - Avaré Nelore } & \multirow{2}{*}{$\begin{array}{l}\hat{\mathrm{m}}_{1}(\%) \\
90,12\end{array}$} & \multirow{2}{*}{$\begin{array}{l}\hat{\mathrm{m}}_{2}(\%) \\
92,98\end{array}$} & \multirow{2}{*}{$\begin{array}{l}\text { Teste } \mathrm{t} \\
-0,45^{\mathrm{NS}}\end{array}$} \\
\hline Babesia bovis & 1 - Avaré Holandês & & & & & \\
\hline & 1 - Avaré Holandês & vs & 2 - P. Pte Holandês & 90,12 & 96,50 & $-1,21^{\mathrm{NS}}$ \\
\hline & 1 - P. Pte Holandês & vs & 2 - P. Pte Nelore & 96,50 & 78,08 & $3,28 *$ \\
\hline & 1 - Avaré Nelore & vs & 2 - P. Pte Nelore & 92,98 & 78,08 & $2,22 *$ \\
\hline \multirow[t]{4}{*}{ Babesia bigemina } & 1 - Avaré Holandês & vs & 2 - Avaré Nelore & 81,80 & 67,45 & $1,13^{\mathrm{NS}}$ \\
\hline & 1 - Avaré Holandês & vs & 2 - P. Pte Holandês & 81,80 & 92,55 & $-1,23^{\mathrm{NS}}$ \\
\hline & 1 - P. Pte Holandês & vs & 2 - P. Pte Nelore & 92,55 & 65,77 & 7,72 * \\
\hline & 1 - Avaré Nelore & vs & 2 - P. Pte Nelore & 67,45 & 65,77 & $0,17^{\mathrm{NS}}$ \\
\hline \multirow[t]{4}{*}{1 - B. bovis } & 2 - B. bigemina & & Avaré Holandês & 90,12 & 81,80 & $0,97^{\mathrm{NS}}$ \\
\hline & & & Avaré Nelore & 92,98 & 67,45 & 2,43 * \\
\hline & & & P. Pte Holandês & 96,50 & 92,55 & $1,22^{\mathrm{NS}}$ \\
\hline & & & P. Pte Nelore & 78,08 & 65,77 & $2,14^{\mathrm{NS}}$ \\
\hline
\end{tabular}

NS Não significativo a $5 \%$ de probabilidade.

* Significativo a $5 \%$ de probabilidade. 
mecanismos pelo qual, nos rebanhos da raça Nelore, a ocorrência de anticorpos anti-B. bigemina seja menor.

Ainda, analisando-se o Quadro 3, constata-se uma diferença significativa para $B$. bovis entre as regiões estudadas, onde os animais da raça Nelore, pertencentes ao Município de Avaré apresentaram maior soroprevalência que os de Presidente Prudente. Avaré, ao contrário de Presidente Prudente, é caracterizada como uma região de predominância de pecuária leiteira e de cruzamento industrial, com a utilização de bovinos de raças $B$. taurus e seus mestiços, caracterizados como raças pouco resistentes a B. microplus. Há, portanto, maior contaminação das pastagens e com isso uma maior chance de inóculo do agente.

\section{Situação imunológica para bovinos Holandes}

A situação imunológica do rebanho Holandês, nos dois municípios, tanto para $B$. bovis, quanto para $B$. bigemina, não é preocupante, existindo pouca probabilidade de existência de surtos pois, nesses municípios, os rebanhos possuíam frequiência de anticorpos acima de 75\% (Quadro 2). Essas regiões, portanto, são caracterizadas como áreas de estabilidade enzoótica, para ambas as espécies para essa raça.

O estudo evidenciou também haver diferença na ocorrência de anticorpos entre a raça Nelore e a raça Holandesa, para ambas as babesias. Logo, a comparação com outras pesquisas torna-se mais fiel à medida que as espécies de $B$. indicus e $B$. taurus forem levadas em consideração na discussão.

Baseando-se nessas considerações, constatou-se que tanto para $B$. bovis quanto para B. bigemina, os resultados da pesquisa flutuaram em comparação aos encontrados por outros pesquisadores, em outras regiões e estados: Rio der Janeiro (Madruga et al.1992), Paraíba (Madruga et al. 1993), Bahia (Araújo 1995), São Paulo (Barci et al. 1995a), Rio Grande do Sul, Santa Catarina, Rio de Janeiro, Bahia, Mato Grosso do Sul, Roraima (Madruga et al. (1995), Paraná (Vidotto et al. 1997), Rio de Janeiro (Cunha et al. 1999) e Santa Catarina (Souza et al. 2002), ora sendo similares, inferiores ou superiores.

\section{Situação imunológica para bovinos Nelore}

Ao contrário da raça Holandesa, a condição imunológica para a raça Nelore é preocupante para a B. bigemina nos municípios de Avaré e de Presidente Prudente onde foram verificadas áreas de instabilidade enzoótica (Quadro 2). Também inspira cuidados, a situação epidemiológica de $B$. bovis em Presidente Prudente a qual se encontra na área marginal, com uma ocorrência de 78,08\% de anticorpos anti-B. bovis. Madruga et al. (2000) descreve em Mato Grosso do Sul frequiência de indivíduos sororeagentes de $72,5 \%$, situação muito parecida com a de Presidente Prudente para $B$. bovis, embora esteja localizada numa área de estabilidade enzoótica a frequiência de anticorpos é baixa, estando os bovinos mais suscetíveis à ocorrência aguda da doença.

À semelhança do ocorrido com bovinos da raça Holandesa, a percentagem de animais possuidores de anticorpos, para ambas babesias, na raça Nelore também flutuou quando comparada às encontradas por outros autores: em Mato Grosso Sul (Madruga et al.1983, 2001), São Paulo (Barci et al. (1995b), Santa Catarina (Dalagnol et al. 1999) e Rio de Janeiro (Madureira et al.
1999, Scofield et al. 1999, Soares et al. 2000), havendo situações de igualdade, superioridade e outras de inferioridade.

A variação da condição imunológica para as Babesias spp no Brasil, mostra a importância do conhecimento da soroprevalência regional que inclusive, poderá se alterar em conformidade à introdução, cada vez maior, de animais de raças $B$. taurus e também por manejos que possam propiciar uma maior difusão da doença, como o controle massivo do transmissor ou por meio de medicamentos como os reguladores de crescimento aliados a utilização de vacinas contra $B$. microplus.

\section{REFERÊNCIAS}

Araújo F.R. 1995. Levantamento sorológico para Babesia bovis (Babes,1888) e Babesia bigemina (Smith E Kilborne, 1893) em bovinos no estado da Bahia. Tese de Mestrado, Universidade Federal da Bahia Salvador. 78p.

Araújo F.R., Madruga C.R., Leal C.R.B., Schenk M.A.M., Kessler R.H., Marques A.P.C. \& Lemaire D.C. 1998. Comparison between enzyme-linked immunosorbent assay, indirect fluorescent antibody and rapid conglutination tests in detecting antibodies against Babesia bovis. Vet. Parasitol. 74:101-108.

Barci L.A.G., Oliveira M.R., Machado R.Z., Oliveira D.A. \& Araújo Filho R.S. 1995a. Epidemiologia da babesiose bovina no estado de São Paulo. I. Estudo em rebanhos produtores de leite tipo B do município de Pindamonhangaba, Vale do Paraíba. Revta Bras. Parasitol. Vet. 3(2):79-82.

Barci A.G., Dell'Porto A., Fujii T.U. \& Machado R.Z. 1995b. Epidemiologia da babesiose bovina no estado de São Paulo: estudo em rebanhos de corte da região do Vale do Ribeira. IX Seminário Brasileiro de Parasitologia Veterinária, Campo Grande, MS, p.205. (Resumo)

Bennett G.F. 1974. Boophilus microplus (Canestrini) (Acaridae: Ixodidae) on the bovine host. I. Mortality during the developmental cycle. Acaralogia 16:643-650.

Corrier D.E., Gonzales E.F. \& Betancourt A. 1978. Current information on the epidemiology of bovine anaplasmosis and babesiosis in Colombia. In: Wilde J.K.H. (ed.) Tick-borne Diseases and their Vectors. Lewis, Tonbridge, p.114-120. (Reprint)

Cunha N.C., Soares C.O., Souza J.C.P., Madureira R.C., Fonseca A.H., Madruga C.R. \& Massard C.L. 1999b. Soroprevalência da Babesia bigemina (Smith \& Kilborne, 1893) (Apicomplexa: Babesiidae) em bovinos na mesorregião do Médio Paraíba do Estado do Rio de Janeiro. XI Seminário Brasileiro de Parasitologia Veterinária, Salvador, Bahia, p.200. (Resumo)

Dalagnol A.A., Martins E., Madruga C.R., Gomes R., Schenk M.A.M., Kessler R.H., Gratão G., Gales M.E., Schenk J.A.P., Andrease M., Bianchini I. \& Miguita M. 1999. Prevalência de agentes da tristeza parasitária bovina em bovinos de corte na região de clima cfb - SC. Agropecuária Catarinense 12(3):46-47.

Kemp D.H., Koudstaal D., Roberts J.A. \& Kerr J.D. 1976. Boophilus microplus. The effect of host resistance on larval attachments and growth. Parasitology 73:123-36.

Kessler R.H. \& Schenk M.A.M. 1998. Carrapato, tristeza parasitária e tripanossomose dos bovinos. Embrapa Gado de Corte, Campo Grande, MS, p.157.

Kurt O. \& Girginkardesler N. 2001. Babesiosis. Turkive Parazitoloji Dergisi 25(1):94-98.

Leite A.M.O., Arnoni J., Silva S.S. Farias N., Cruz H. \& NishiKawa H. 1989. Serological study of bovine babesiosis in a marginal area of Brasil. Proc. 8th National Veterinary Hemoparasite Disease Conference, St. Louis, p.624-635.

Madruga C.R., Aycardy E. \& Putt N. 1983. Epidemiologia da Anaplasmose e Babesiose em bovinos da região de Cerrado do Estado de Mato Grosso do Sul. I. Prevalência. Arq. Bras. Med. Vet. Zootec. 35(5):631-640 .

Madruga C.R., Braga M.M., Lima L.A.F., Moraes J.L.C., Oliveira D.B. \& Massard L.C. 1992. Prevalência de anticorpos contra Babesia bovis e B. 
bigemina em bovinos no Estado do Rio de Janeiro. $22^{\circ}$ Congr. Bras. Med. Veterinária, Curitiba. (Resumo 285)

Madruga C.R., Honer M.R., Andreotti R., Araújo F.R. \& Santarém V. 1993. Simulação e sorologia no mapeamento da instabilidade endêmica das babesioses: um estudo nas regiões do Boqueirão e Cairiri, Estado da Paraíba. VIII Seminário Brasileiro de Parasitologia Veterinária, Londrina, Paraná. (Resumo P1)

Madruga C.R., Kessler R.H., Schenk M.A.M., Honer M.R. \& Miguita M. 1995. Análise de testes de conglutinação rápida para detecção de anticorpos contra Babesia bovis e B. bigemina: Arq. Bras. Med. Vet. Zootec.47(5):649-657.

Madruga C.R., Marques A.P.C., Queiroz R.A. \& Vaz E.C. 1997b. Avaliação de um teste ELISA para detecção de anticorpos contra Babesia bigemina em bovinos de áreas de estabilidade e instabilidade enzoótica. Revta Bras. Parasitol. Vet. 6(1):302.

Madruga C.R., Araújo F.R., Marques A.P.C., Carvalho C.M.E., Cusinato F.Q., Crocci A.J., Kessler R.H. \& Miguita M. 2000. Desenvolvimento de uma prova de imunoadsorção enzimática para deteç̧ão de anticorpos contra Babesia bovis. Pesq. Vet. Bras. 20(4):167-170.

Madruga C.R., Araújo F.R., Marques A.P.C., Carvalho C.M.E., Crocci A.J., Queiroz, R.A., Miguita M. \& Umaki A.C.S. 2001. Evaluation of ELISA for detection of antibodies to Babesia bigemina in cattle and its application in an epidemiological survey in Brazil. Pesq. Vet. Bras. 21(2):72-76.

Madureira R.C., Soares C.O., Manera G.B., Souza J.C.P., Madruga C.R., Fonseca A.H. \& Massard C.L. 1999. Soroprevalência da Babesia bigemina (Smith \& Kilborne, 1893) (Apicomplexa: Babesiidae) em bovinos na mesorregião Noroeste Fluminense. XI Seminário Brasileiro de Parasitologia Veterinária, Salvador, Bahia, p.198. (Resumo)

Mahoney D.F. \& Ross D.R. 1972. Epizootiological factors in the control of bovine babesiosis. Aust. Vet. J. 48:292-298.

Mahoney D.F. 1975. The diagnosis of babesiosis in Australia, p.49-62. In: Wells E.A. (ed.) Workshop on Hemoparasites (Anaplasmosis and Babesiosis). CIAT, Cali, Colombia.

Roberts J.A. 1968. Resistence of cattle to tick Boophilus microplus (Canestrini). II. Stages of life cycle of the parasite against which resistance is manifest. J. Parasitol. 54:667-673.
Sartor I.F., Faccini J.L.H., Kuchembuck M.R.G. \& Curi P.R. 1992. Estudo comparativo da resistência ao carrapato Boophilus microplus (Canestrini) (Acari) em bovinos das raças Gir, Holandesa e mestiços $1 / 2$ gir-holandês. Vet. Zootec. 4:25-33.

Scofield A., Soares C.O., Souza J.C.P., Silva W.C.P., Madureira R.C., Fonseca A.H. \& Madruga C.R. 1999. Soroprevalência da Babesia bovis (Babés,1888) (Apicomplexa: Babesiidae) em bovinos na mesorregião Noroeste Fluminense. XI Seminário Brasileiro de Parasitologia Veterinária, Salvador, Bahia, p.199. (Resumo)

Smith R.D. 1980. Epidemiologia de la anaplasmosis y babesiosis bovinas. In: II Reunion Interamericana de Directores de Salud Animal, San José, Costa Rica, set. 8-12.

Soares C.O., Souza J.C.P., Madruga C.R., Madureira R.C., Massard C.L. \& Fonseca A.H. 2000. Seroprevalence of Babesia bovis in cattle in the Norte Fluminense region. Pesq. Vet. Bras. 20:75-79.

Souza A.P., Surkamp V., Bellato V., Sartor A.A. \& Farias M.L. 2002. Prevalência de anticorpos anti-babesia em bovinos no Planalto Santa Catarina. Revta Ciênc. Agrovet. 1:21-23.

Suarez M.H., Alonso M.C., Pelaez R.M., Sanches B.P., Bravo Jr G. \& Sanchez A.S. 1997. Pesquisaje de Babesia en trabajadores Cubanos, agropecuarios y donantes en la provincia de Ciego de Avila. Revta Med. Tropical 49(2):130-135.

Vidotto O., Andrade G.M., Amaral C.S.H., Barbosa C.S., Freire R. L., Rocha M.A. \& Vidotto M.C. 1997. Freqüência de anticorpos contra Babesia bovis e B. bigemina e Anaplasma marginale em rebanhos leiteiros da região de Londrina, Paraná. Arq. Bras. Vet. Zootec. 49:655-659.

Wagland B.M. 1979. Host resistence to cattle tick Boophilus microplus in Brahman (Bos indicus) cattle. IV. Ages of ticks rejected. Aust. J. Agric. Res.30:211-218.

Willadsen P. 1986. Mecanisms and genetics of host resistance to ticks. Proc. 3rd World Congr. Genetics Applied to Livestock Production, Lincon, Nebrasca, p.571-580.

Wright I.G. \& Goodger B.V. 1988. Pathogenesis of babesioses, p.100-118. In Ristic M. (ed.) Babesiosis of Domestic Animals and Man. CRC Press, Boca Raton, Flórida. 